\title{
Construção social da violência e a negação da civilidade
}

Antonio Mateus de Carvalho Soares ${ }^{1}$

Resumo: Este artigo de natureza teórica, tem como objetivo problematizar o conceito de violência e suas mutações através dos tempos. Apresentamos as diversas abordagens que tem caracterizado o fenômeno na literatura sociológica, de modo a situar as complexidades deste conceito. Como fenômeno social a violência é construída na relação entre os homens e se processa de forma a romper com os próprios códigos de ordens produzidos por esta relação. As compreensões expressas neste trabalho aprofundam análises sobre a violência e redimensionam os efeitos que ela produz para a condição humana. Neste contexto, manifestaremos como a violência se afirmou como uma questão pública que se insere entre as preocupações das agendas governamentais, seus jogos de poder, as relações de força e como movimento de fronteiras tênues entre o legal e o ilegal. $\mathrm{O}$ artigo se divide em três partes: 1- Violência e as intercalações entre civilidade e incivilidade, em que apresentamos as influências do contrato social e do Estado moderno, na caracterização da violência; 2- A violência como uma noção polissêmica, manifestando diversos conceitos e intensidades deste fenômeno; 3- Classificar e distinguir violências e crimes, na qual explicitamos os principais elementos que diferenciam a ação violenta, através das diversas formas de agressão, da ação criminal, postulada em lei. Além de apresentar diversos conceitos sobre a violência, o artigo afirma que ela esvazia o sentido da política, como ação dialógica.

Palavras chaves: conceito. violência. sociedade. civilidade

Abstract: This article is theoretical in nature, to problematize the concept of violence and their changes over time. We present the various approaches that have characterized the phenomenon in sociological literature, in order to situate the complexities of this concept. Violence as a social phenomenon is built on the relationship between people and processes in

\footnotetext{
${ }^{1}$ Professor Adjunto da Universidade Federal do Sul da Bahia - UFSB. Doutor em Ciências Sociais pela Universidade Federal da Bahia - UFBA. E-mail:. antoniomateuscs@gmail.com
}

Latitude, Vol. 8, nº 1, pp. 33-62, 2014

DOI: https://doi.org/10.28998/2179-5428.20140103 
order to break the codes themselves orders produced by this relationship. Understandings expressed in this paper deepen analysis on violence and resize the effects it produces for the human condition. In this context, manifest as violence has emerged as a public issue that falls between the concerns of government agendas, their games of power, relations of force and motion as thin line between legal and illegal. Produced through the literature, the article is divided into three parts: 1 - Violence and its intercalation between civility and incivility, where we present the influences of the social contract and the modern state, the district and characterization of violence ; 2 - Violence as one polysemous term expressing various concepts and intensities of this phenomenon ; 3 - Sort and distinguish violence and crimes in which we make explicit the main elements that differentiate violent action, through various forms of assault , criminal action, premised on law. In addition to presenting diverse concepts of violence, the article states that she empties the meaning of politics, as dialogical action.

Keywords: concept . violence. society. civility

\section{Introdução}

A violência assim como a política, ${ }^{2}$ institui seus sentidos através da relação entre os homens. Entretanto ela é o avesso da política, pois em sua instituição ela nega o diálogo e a palavra. Paradoxalmente, a violência é construída na sociedade e se processa de forma a romper com os próprios códigos de ordens produzidos por ela. A violência emerge como uma agressão ao indivíduo e ao coletivo. Deste modo, este artigo, além de aprofundar análises sobre a violência enquanto fenômeno social, redimensionará os efeitos que ela produz para a condição humana e suas

\footnotetext{
2 Segundo Arendt (2006),a política constitui-se no horizonte de interpretação da violência, que não é natural, pessoal ou irracional. A violência é instrumental e se contrapõe ao poder e à política, tendo em vista que na ausência da palavra e do discurso a violência impera e dilui a política.
} 
associações com as dimensões da civilidade, incivilidade e descivilidade ${ }^{3}$. Visa demonstrar a amplitude do conceito sociológico de violência, suas classificações, compreendendo como ela se transforma em crime.

A violência, e as representações ${ }^{4}$ no contexto contemporâneo, constituem-se num dos maiores problemas sociais que afeta a vida em sociedade, e exerce efeitos negativos ${ }^{5}$ sobre a convivência social e a funcionalidade das instituições. "A violência ocupa um lugar central na luta pela posse do presente, pela compreensão da experiência

3 A noção de civilidade, assim como suas derivações, recebe influência de Norbert Elias $(1994,1997)$, que ao analisar os diferentes estágios do processo civilizador, destaca a influência das estruturas dos processos sociais em relação ao processo civilizador do indivíduo. Ao referenciarmos o conceito de civilidade, levamos em consideração o respeito às normas de convívio, a lei, a moral e a obediência às regras de urbanidade e comportamentos. A incivilidade é a negação da civilidade: "se um homem da atual sociedade civilizada ocidental fosse, de repente, transportado para uma época remota de sua própria sociedade, tal como o período medievo-feudal, descobriria nele muito do que julga 'incivilizado' em outras sociedades modernas." (ELIAS, 1994, p. 13, grifo do autor). A descivilidade é compreendida como um fenômeno que engloba um processo de reversão da civilidade, em que o Estado Civil (GRAMSCI, 2001), buscando exercer o seu controle, se utiliza da ação violenta para manter a sua autoridade legítima; é o retorno à condição de violência para combater a própria violência.

${ }^{4}$ Moscovici (1961) e Jodelet (2001) defendem que as representações são vistas como produtos sociais de uma realidade exterior que se consolida por meios de informações, imagens, opiniões, valores, atitudes em relação a um determinado objeto. É um processo de apreensão da realidade e de elaboração psicológica e social dessa realidade.

5 Há alguns autores, a exemplo de Theophilos Rifiots (2006), que sem desconsiderar a dimensão negativa da violência, expressa também sua dimensão positiva. Para este autor a "positividade" da violência, pode atuar como uma espécie de força dispersiva, voltada para a manutenção das diferenças, em contraponto ao controle da homogeneização que a centralidade dos poderes pode instaurar. Rifiotis, ainda esclarece que os trabalhos de Pierre Clastres (1980), foram pioneiros em tratar da dimensão positiva da violência, particularmente quando analisou a noção de "sociedades contra o Estado", utilizada na análise da guerra das sociedades indígenas. Para este Clastres, o Estado, funciona como uma máquina de unificação, enquanto a violência e, em particular a guerra, atuaria no sentido inverso. 
contemporânea, com seus mundos marginais, a sua dimensão episódica e fragmentária, um tempo marcado pela diferença, pela falta de finalidade das formações sociais". (RIFIOTIS, p. 1, 2006). O crescimento da violência tem mobilizado discussões no meio acadêmico e nos diferentes âmbitos da sociedade civil, colocando o tema na prioridade da agenda pública das políticas governamentais e no âmbito das pesquisas sociais. A manifestação do fenômeno no contexto contemporâneo é vista como um mal que atinge a vida social e que deve ser combatido, pois agride a condição humana e os direitos civis e sociais, não se restringindo apenas às relações de agressividade e incivilidade entre grupos e indivíduos, mas também a conflitos nas formas de controle que as instituições sociais exercem ou deviam exercer para manter a autoridade e a norma social. Como fenômeno pluricausal, a compreensão da violência demanda interfaces com outros temas complexos, como os direitos da cidadania, o exercício dos direitos humanos e as condições de exercício da justiça social, da segurança pública e do Estado.

A definição de violência é ampla e polissêmica. A palavra violentia é oriunda do século XIII, mesmo sabendo que ela enquanto ação existe antes disto, foi derivada do latim vis, designando a "força" ou o "vigor", e seu uso pode definir uma relação de força, submissão e constrangimento a outrem, se expressando de forma material ou imaterial.

Violência vem do latim violentia, que significa violência, caráter violento ou bravio, força. $O$ verbo violare significa tratar com violência, profanar, transgredir. Tais termos devem ser referidos a vis, que quer dizer força, vigor, potência violência, emprego de força física, mas também quantidade, abundância, essência ou caráter essencial de alguma coisa. (MICHAUD, 1989, p. 8).

Portanto, parte da complexidade da análise da violência se origina da própria dificuldade de compreender o comportamento humano. As primeiras tentativas conceituais, como analisa Robert Muchembled (2012), afirmavam a violência como elemento intrínseco à própria existência humana, entendendo que todos os seres vivos são movidos por comportamentos predatórios e instintivos de defesa, quando são ameaçados. Neste sentido, o uso da violência seria uma forma não de 
aniquilar a vida, mas de garantir a conservação da existência, e uma resposta ao medo, à frustração, à inveja, vingança ou perda de esperança. Para Erich Fromm (1975), há também uma forma de violência definida como compensatória, praticada por indivíduos acometidos de impotência, e que desejam reverter a sua fraqueza em força através da ação violenta. Segundo este autor, o homem é o único primata capaz de matar e torturar membros de sua espécie sem nenhuma razão, por puro prazer, e tal comportamento faz da violência um fenômeno intrínseco à condição humana.

Para Hannah Arendt (2010), a condição humana se refere às formas de vida que o homem impõe a si mesmo para sobreviver, exercendo ações que buscam suprir as necessidades de sua existência e que variam no espaço e no tempo. As ações e comportamentos humanos estão condicionados por contextos sócio-históricos. Segundo Arendt (2010, p. 35), "até mesmo aqueles que condicionam o comportamento de outros homens tornam-se condicionados pelo próprio movimento de condicionar".

Na condição humana, instituída no estado de natureza, "o homem era lobo do homem", ele já nascia com o instinto de promover o mal que era acelerado pelo desejo de competição, pela vontade da posse, domínio e poder. Assim, violência era uma ação de preservação da existência. Segundo Thomas Hobbes (2002), neste estágio da natureza o homem seria naturalmente egoísta e predisposto à violência, em um ambiente marcado pela luta de todos contra todos, pois no "estado de natureza" não havia qualquer direção ou mediação de governo, estando os indivíduos incitados à violência e à selvageria.

A natureza deu a cada um o direito a tudo; isso quer dizer que, num estado puramente natural, ou seja, antes que os homens se comprometessem por meio de convenções ou obrigações, era lícito cada um fazer o que quisesse, e contra quem julgasse cabível e portanto possuir, usar e desfrutar tudo que quisesse ou pudesse obter. Ora, como basta um homem querer uma coisa qualquer para que ela já lhe pareça boa, e o fato dele a desejar já indica que ela contribui, ou pelo menos lhe parece contribuir, para sua conservação [...] De tudo isso então decorre 
que, no estado de natureza, para todos é legal ter tudo e tudo cometer. E é este o significado daquele dito comum, 'a natureza deu tudo a todos', do qual, portanto, entendemos que, no estado de natureza, a medida do direito está na vantagem que for obtida. (HOBBES, 2002, p. 32).

Discordando de Hobbes, Jean Jacques Rousseau afirma que "o homem é bom e a sociedade o corrompe" (ROUSSEAU, 1978, p. 25). Para este autor, no estado da natureza o homem era bom, vivia em harmonia com os demais, não havia estado de guerra. Foi, portanto, o surgimento da propriedade privada que instituiu os conflitos de interesses distintos, gerando a necessidade do estabelecimento de um contrato entre os homens. Para John Locke (2005), o homem não era bom nem mal, seu temperamento oscilava entre a racionalidade e a ponderação e a irracionalidade e a agressividade. Para Locke (2005), o que faltava, no estado da natureza, eram princípios de racionalidade para julgar as controvérsias advindas da irracionalidade do homem.

As dialéticas apontadas pelos teóricos do contratualismo trazem reflexões sobre o comportamento do homem no estado da natureza, caracterizado pela ausência da lei soberana e tendo a ação violenta como medida de autopreservação do homem e de sua propriedade instituída como barbárie. A condição humana estaria assegurada dentro de princípios em que a ação de uma pessoa seria limitada pela força da outra, em um movimento legítimo de autopreservação, em que não existem regras, normas, direitos e deveres estabelecidos, constituindo um ambiente em que, na ausência de processos e valores socializadores, o uso da força violenta expressava processos de incivilidade manifestos através de desrespeitos, desordens, agressões físicas e verbais, homicídios, entre outros tipos de comportamento que fragilizam as relações humanas.

Neste contexto de conceber a violência como uma ação intrínseca à condição humana, este artigo afirma que dialeticamente a violência emana do homem e atinge o próprio homem, tanto objetivamente como subjetivamente. No esboço traçado para esta discussão, subdividimos este artigo em três vertentes: o primeiro item dimensiona os efeitos que a violência produz para a condição humana e suas associações com a noção de civilidade e incivilidade; o segundo como já referenciando demonstra as 
dialéticas e polissemias em torno da violência como categoria social dinâmica e complexa; e, por fim, o terceiro item recupera a amplitude das convergências e divergências entre os conceitos de violência e crime, suas classificações e representações com base em literatura referenciada.

\section{Violência e as intercalações entre civilidade e incivilidade}

A criação de mediações que limitassem o ímpeto do homem no estado da natureza induziu à formação de um contrato social como instrumento regulatório dos interesses distintos entre indivíduos, que, para Rousseau (1978), representa um pacto de direito político em que prevaleceria a soberania da sociedade e a vontade coletiva representada pelo Estado Civil ${ }^{6}$, distante do interesse singular e organizado para garantir o interesse de todos. Tal evolução levaria o comportamento humano a substituir a conduta do "instinto" por condutas de justiça, que recusa a violência no convívio humano. A formação desse pacto social implicou a organização da sociedade civil como uma arena de ações coletivas, organizadas por instituições criadas em torno de interesses e propósitos coletivos. A sociedade civil passaria a sistematizar e fiscalizar as formas contratuais de governo, baseada na regra da lei, através da demarcação e de regulamentações para a organização social, em que os direitos e deveres se estabeleceriam como diretrizes para o controle e o ordenamento social.

O controle do Estado e a organização da sociedade civil exerceriam um pacto de sujeição do individuo a soberania estatal, não permitindo a violência "natural". O Estado Civil seria a instituição responsável pelo controle da violência, e só ele, em nome do bem-estar coletivo, poderia

${ }^{6}$ Estado civil e sociedade civil são conceitos catalisadores de ampla discussão no âmbito da teoria social. Foram submetidos à intensa crítica por Karl Marx e Friedrich Engels no século XIX, que demonstraram as razões históricas do seu surgimento. A concepção de Marx e Engels (1999), sintetizada no Manifesto Comunista sobre o Estado, expressa que o poder executivo moderno não passa de um comitê para gerenciar os assuntos comuns da burguesia. Engels (1984), em $A$ origem da família, da propriedade privada e do Estado, defende que a força da coesão da sociedade civilizada é oriunda do Estado, e este é gerenciado pela classe dominante que reprime a classe oprimida e explorada. Os trabalhos de Gramsci (2001) também contribuem em elevada medida para a discussão entre o Estado e a sociedade civil.

Latitude, Vol. 8, nº 1, pp. 33-62, 2014. 
exercer a violência legítima. No pensamento liberal, o contrato estatal implicaria o surgimento simultâneo da sociedade política e da sociedade civil7 . Para Gramsci (2001), o conceito de sociedade civil é inseparável da luta entre as classes sociais, e sua construção integra sua mais densa reflexão sobre o "Estado ampliado". $\mathrm{Na}$ concepção gramsciana, não há oposição entre sociedade civil e Estado; há uma relação de extensão e ajustamentos.

Conforme Gramsci (2001), a sociedade política se elabora no seu sentido estrito. Através da coerção estatal ela é produzida por um conjunto de aparelhos nos quais a classe dominante detém e exerce o "monopólio legal" - aparelhos coercitivos ligados às forças armadas e à polícia. Corresponde a uma dimensão marcada pela coerção, pela imposição, pelo uso da força e da violência, quando necessária. Os governos modernos que ocupam a esfera estatal e se sustentam no sufrágio universal usam dessa hegemonia para impor o "monopólio legal" frente à sociedade. Segundo a concepção gramsciana, a sociedade civil é formada por um conjunto de instituições responsáveis pela representação de diferentes tipos de interesses (privados, de grupos e ou segmentos particulares comprometidos com a manutenção ou a ruptura da ordem). Esses segmentos e grupos sociais, apoiados em interesses específicos de classe, se encontram comprometidos com a difusão de suas ideologias (partidos, igrejas, escolas, entre outras instituições).

A noção de "Estado ampliado", em Gramsci (2001), é composta pela relação entre a sociedade política e a sociedade civil, ou seja, é formada pela hegemonia conquistada - ao mesmo tempo - pela coerção e pela conformidade. É um composto de correlações de forças, que pode servir para manter ou transformar as relações sociais de acordo com os interesses da classe hegemônica. As classes sociais lutam por hegemonia, na conquista de aliados para seus projetos, almejando o consenso e uma direção comum. Esse movimento se expressa nas esferas do Estado, na forma como os três poderes: Executivo, Legislativo e Judiciário se

\footnotetext{
${ }^{7}$ Não é objetivo deste estudo aprofundar a problematização sobre o conceito de sociedade civil e Estado, mas apenas sinalizar a sua evolução e importância constitutiva para o processo civilizatório e para a legitimação das instituições de ordem.
} 
comportam face às lutas sociais que ocorrem fora da esfera estatal movimentos e manifestações sociais, partidos políticos, sindicatos etc.

A organização do Estado e a complexidade da sociedade civil denotou um novo estágio, em que a (des)civilidade, a força violenta, o comportamento e os impulsos humanos passam a ser disciplinados por quadros normativos e contratos sociais. A organização civil estaria presente no governo, manifestaria novas formas de controle guiadas por instituições e pela presença de um Estado, que arbitraria sobre a sociedade. Para Norberto Bobbio (1987), a formação da sociedade civil constitui o momento intermediário entre o individuo e o Estado, as transformações sociais mobilizadas pela constituição da sociedade civil indicariam novos horizontes para a vida social, no que se refere aos direitos individuais, às regras de conduta, ao respeito à lei e às formas de controle de condutas desviantes.

É nesse sentido que os elementos e as instituições da sociedade civil assumem um papel tanto representativo quanto ético, integrando e educando os indivíduos para a vida cívica, instituída por direitos e deveres comuns a todos, aproximando cada vez mais os indivíduos do sentido da sociedade civil, requerendo do indivíduo:

[...] regularidade de comportamento, regras de conduta, respeito pela lei, e controle da violência. Assim, uma sociedade civil era sinônimo de sociedade cortês, sociedade na qual estranhos agem de uma maneira civilizada com relação aos outros, tratando cada um com respeito mútuo, tolerância e confiança, uma sociedade na qual o debate racional e a discussão se tornam possíveis. (KALDOR, 2003, p. 17).

A organização da sociedade civil é orientada pelo respeito às normas de convívio, obediência às regras de urbanidade e comportamentos marcados por formas de agir civilizadas e obedientes às regulamentações de um Estado. Este se responsabiliza pelo controle da violência, sem, contudo, extinguí-la, tendo em vista que o controle social como uma força coercitiva constitui-se em violência legítima, exercida pelo Estado e protegida pela lei. Ao instituir-se como agente do processo civilizatório, o 
Estado civil (GRAMSCI, 2001) apresentaria o reverso da civilidade, que é o processo de "descivilização", compreendido como um fenômeno que engloba o primeiro, em que o Estado, buscando exercer o seu controle, se utiliza da ação violenta para manter a sua autoridade legítima.

O processo de civilização do Estado, a Constituição, a educação e, por conseguinte, os segmentos mais numerosos da população, a eliminação de tudo o que era ainda bárbaro ou irracional nas condições vigentes, fossem as penalidades legais, as restrições de classe à burguesia ou as barreiras que impediam o desenvolvimento do comércio - este processo civilizador devia seguir-se ao refinamento de maneiras e à pacificação interna do país pelos reis. (ELIAS, 1994, p. 62).

Para Robert Muchembled (2012, p. 9), “o poder destrutivo da violência pode ser inibido pelas civilizações que se organizarem para impor a ordem". Tanto Elias (1994, 1997) como Muchembled (2012) coincidem na tese do "processo civilizatório", ao afirmarem que o adestramento cultural e o controle social são indispensáveis para o desenvolvimento de modos padronizados de conduta. A ordem social é vista por esses autores como desmobilizadoras de conflitos entre os indivíduos, pois disciplina o comportamento e controla os impulsos e desejos antissociais com base na moral e valores, promovendo o surgimento de espaços pacificadores e civilizados, o que viria inibir os comportamentos desviantes e violentos. Para Elias (1997), grande parte dos cidadãos não tolera os atos violentos como forma de resolver os conflitos sociais, entendendo que a civilidade possibilita um maior esclarecimento dos cidadãos sobre as noções de direito, respeito e justiça, assim como em relação à responsabilidade do Estado no controle da violência.

A passagem do "estado de natureza" para o "Estado civil" (LOCKE, 2005), mediada por regras de convívio e direitos, foi determinante para alterações na vida social: evolução política, desenvolvimento das instituições modernas, emergência dos direitos, enquanto detentor de valor jurídico universal (BOBBIO, 1992). Esta passagem foi marcada por processos distintos que evoluem desde a completa ausência de cortesia e 
solidariedade, na qual inexistem questionamentos sobre a conduta brutalizada, até a civilidade (instituição de regras de convívio e polidez nas relações sociais, com evolução dos códigos de ética e de respeito) e descivilização (transgressão da norma instituída, ruptura dos direitos humanos, retorno à condição de violência para combater a própria violência). Processos que alteraram os significados do ato violento, que deixam de ser apreendidos como uma condição necessária à autopreservação do indivíduo em seu estado de liberdade natural, como afirma Hobbes (2002), para expressar ações desumanizadoras, agressivas e com múltiplas formas de representação social e política.

\section{Violência: uma noção polissêmica}

A violência, ancorada nas relações sociais e nas tramas intersubjetivas, é um conceito amplo, transitivo e recorrente das circunstâncias individuais e sociais. Como reflexo do ambiente cultural e histórico, a análise da violência está também associada a outros conceitos sociais da ordem, como o poder, a força e a potência, que convergem para o entendimento de ações e de comportamentos humanos que desafiam o institucionalizado, o moral e o ético. A associação destes conceitos com a finalidade de problematizar o entendimento da violência. Nesta direção, é fundamental para a compreensão de poder, força e potência o uso das noções conceituais referenciadas principalmente nos trabalhos de Arendt (1994), Foucault (1998) e Agamben (2002), no que se refere ao conceito de violência e seus desdobramentos. As tentativas de interpretação conceitual dessa noção são sempre marcadas pela diversidade de práticas e ações caracterizadas por contextos específicos. Portanto, a violência é um fenômeno social e culturalmente constituído ao longo do processo civilizatório de uma sociedade, não é recente ${ }^{8}$ e sua incidência progressiva na contemporaneidade induz a questionamentos que buscam explicitar as formas concretas como se manifesta o fenômeno.

\footnotetext{
${ }^{8}$ Há muitos séculos já existem guerras, genocídios, torturas, intolerâncias raciais e culturais e outros meios agressivos de dominar e subjugar. A violência sempre esteve presente no curso da História, quando não se expressando de forma branda e sangrenta, se evidenciando na miséria, na injustiça social, na humilhação e nas diversas formas de desrespeito.
} 
A noção de violência é, portanto, relativa, plural e contingente às circunstâncias históricas de sua manifestação; e é muitas vezes difusa, o que dificulta a sua definição. Manifestada historicamente em contextos de incivilidade, descivilidade, agressividade ${ }^{9}$ e em tantas outras situações de constrangimento, a violência atualmente aparece naturalizada na própria sociedade civil, quando os atos violentos não são mais "exceções", mas manifestações práticas do cotidiano das pessoas, que normalizam gradativamente a ação violenta. Foucault (1998) analisa o processo de normalização da violência, não por ser oficial ou legal, mas por ser utilizada como meio de manutenção de relações de poder na dinâmica social.

O processo de normalização incorpora distorcidamente a violência no âmbito das instituições sociais como uma conduta corriqueira e "aceitável", o que supõe que a apreensão do sentido da norma implícita "às situações de violência" resulte das formas concretas como os indivíduos agem, em situações específicas, explicitando regras de poder (implícitas ou explícitas), de forma a compreender o fenômeno do ponto de vida das mudanças da ordem social e suas formas de reprodução.

Como uma prática contraditoriamente humana, a violência revelase desqualificadora das formas de racionalização da vida social. A violência resulta, consciente ou inconscientemente, de dispositivos sociais e convenções sociais construídas, que criam necessidades materiais e imateriais, as quais, quando não alcançadas, geram conflitos, tensões e frustrações que potencializam a reprodução da violência, manifestando-se na forma de condutas desviantes que dilaceram a moral, os valores e corroem as relações de sociabilidade.

Como manifestação e objetivação contraditória de construção/ desconstrução de relações sociais, o fenômeno da violência é influenciado pela mediação de aparelhos culturais, econômicos e políticos que atuam

9 Segundo Robert Muchembled, (2012, p. 9), “a violência se distingue da agressividade, que é uma potencialidade de violência cujo poder destrutivo pode ser inibido pelas civilizações - se assim decidirem, e quando encontram uma adesão suficiente dos interessados para impor suas visões". 
sobre a conduta humana e sobre a ordem social expressa em um campo de disputa, marcado por "relações de poder que influenciam comportamentos e permeiam as interações entre os grupos e as classes" (FOUCAULT, 1998, p. 38-39). Ainda segundo este autor, numa sociedade caracterizada por campos de disputa, a violência é percebida como um meio de adulterar a ordem vigente e produzir mecanismos de controle alternativos para impor sua força que desagrega e agrega, desconstrói e constrói novas ordens e representações sociais. ${ }^{10}$ E nesse jogo social, empodera ou vulnerabiliza indivíduos, fortalece ou dissolve grupos.

A violência, na perspectiva de Foucault (1998), se produz na dinâmica dos jogos de poder e se mostra cada vez mais difusa na sociedade, envolvendo cada vez mais um número maior de pessoas, estruturando-se cada vez mais em terrenos incertos da vida social e transitando entre fronteiras ${ }^{11}$ do legal e ilegal, lícito e ilícito, formal e informal, ${ }^{12}$ ampliando a gravidade de dramas sociais como a exclusão social, a segregação urbana, a pobreza e a vulnerabilidade social.

Associada ao funcionamento das redes de poder, a violência mostra-se presente na construção da própria sociedade e na construção das relações interpessoais, institucionais, entre as individuais e as coletivas. A sociedade se estrutura com base em relações econômicas e relações de reprodução cultural que, por sua vez, expressam relações de poder. Conforme indica Foucault (2003), as relações de poder são constitutivas da sociedade e estão presentes nas relações humanas, nas contradições de classes, de sexo, de gênero, de etnia, nas interações simbólicas, culturais, institucionais, profissionais e afetivas. O exercício do poder, para Foucault (1998, p. 24), consiste em "conduzir condutas", e essas são, ao mesmo

\footnotetext{
${ }^{10}$ Segundo Abric (1998, p. 28, grifo do autor), “a representação consiste numa visão funcional do mundo, que, por sua vez, permite ao indivíduo ou ao grupo dar um sentido às suas condutas e compreender a realidade através de seu próprio sistema de referências, permitindo assim ao indivíduo de se adaptar e de encontrar um lugar nesta realidade".

11 Para Feltran (2008), as fronteiras não demarcam uma divisão estanque, mas regulam os modos de relação, os fluxos de pessoas, mercadorias e discursos.

12 Machado da Silva (2004), Misse (2006), Telles (2011) e Feltran (2008) advertem sobre os problemas analíticos que a violência produz no âmbito das fronteiras e distinções entre atos ilegais e ilícitos.
} 
tempo, um ato de "conduzir" os outros e a maneira de se comportar num campo social mais ou menos aberto, de possibilidades.

$\mathrm{O}$ poder inerente às relações sociais é geralmente compreendido e utilizado como potência mobilizadora da força e substrato da violência, quando se direciona a potencializar as diferenças que hierarquizam e discriminam os homens, fortalecem os estigmas e ampliam as desigualdades sociais, e dilui o espaço público como lugar do diálogo, aniquilando o entendimento entre os homens pelo uso da palavra ${ }^{13}$. O verdadeiro sentido do poder deve ser compreendido como possibilidade de reverso dessas situações, quando concebido como instrumento político de empoderamento das minorias sociais, ressignificador de práticas e restituidor da ação coletiva. Desse modo, a depender do uso e da compreensão que se faz do poder, contém ao mesmo tempo a violência e a antiviolência, a construção e a desconstrução de padrões de convívio na sociedade.

As relações que definem e separam poder, força e violência se estabelecem na própria execução do comportamento humano e na interpretação que realizamos deste comportamento. Para Arendt (1994), o que define e separa a violência do poder é a dimensão da política, que está ausente em situações de violência e presente em relações de poder. Para essa autora, assim como para Foucault (1998), a violência distingue-se do poder, pois ela é utilizada em relações sociais desiguais e hierarquizadas, em que não há liberdade, sendo compreendida como dispositivo de controle e subjugação.

O poder só é efetivado enquanto a palavra e o ato não se divorciam, quando as palavras não são vazias e os atos não são brutais, quando as palavras não são empregadas para velar intenções, mas para revelar realidades e os atos não são usados para violar e destruir, mas para criar relações e novas realidades. (ARENDT, 2006, p. 212).

\footnotetext{
${ }^{13}$ A noção de espaço público - lugar do diálogo - tem sua base conceitual em Arendt (2006, p. 26), que afirma que "o termo público significa o próprio mundo, na medida em que é comum a todos nós e diferente do lugar que nos cabe dentro dele, lugar da política, deve reunir pessoas para argumentarem e definirem seus objetivos comuns".
} 
$\mathrm{Na}$ concepção arendtiana, o poder não subjuga, e quando é utilizado para este fim ele deixa de ser poder e se transforma em potência, que não pode ser confundida com poder. Potência é a força de um homem ou de um coletivo que pode se voltar contra o poder instituído. O poder pertence ao mundo cotidiano das relações entre os indivíduos. Para Foucault (1998), só há relação de poder entre pessoas livres. Entretanto, o autor reconhece que o poder pode ser confundido como potência e se transformar em extensão da violência, quando é utilizado para obter a sujeição e a domesticação do outro, quando o poder se transformar em biopoder (poder sobre a vida) ${ }^{14}$, em que as pessoas passam a ser governadas para que se possa obter o máximo de suas energias vitais.

A violência é a instrumentalização da potência e da força com vista à sua ampliação, e a força é a energia liberada, que pode ser utilizada para fortalecer ou não as relações sociais. A violência é conduzida e imposta pelo uso da força, não só a força física, mas também a simbólica, sendo uma ação destrutiva que ameaça a autoridade e o poder. Ao compreendermos a violência como uma transgressão dos padrões de civilidade, mediada pela força, quanto maior a concentração e direcionamento do uso da força, maior será a intensidade agressiva da conduta violenta. Neste sentido, Ives Michaud (1989), em seu livro La Violence, após explorar os mais diversos sentidos da violência, de forma similar a Hannah Arendt, afirma que a violência pode ser definida como um emprego de "força desmedida", algo que ultrapassa e transgride a ordem estabelecida, instituindo a "força não qualificada" (MICHAUD, 1989, p. 12), que subverte a ordem e dissemina o clamor através de múltiplas formas de agressão.

A violência, na perspectiva de Arendt (1994), expressa a deterioração da política, com a ausência da palavra e do discurso, expressões efetivas do exercício do poder como constitutivos sociais. A humanização das pessoas opera através da "palavra e do discurso"

${ }^{14}$ Foucault (1926-1984) cunhou o conceito de biopoder e biopolítica, explicitados pela primeira vez no capítulo 1 "A defesa da sociedade" do livro História da sexualidade. $\mathrm{O}$ biopoder se refere à prática dos estados modernos e sua regulação dos que a ele estão sujeitos por meio de "uma explosão de técnicas numerosas e diversas para obter a subjugação dos corpos e o controle de populações" (FOUCAULT, 1999, p. 34). 


\section{Construção social da violência e a negação da civilidade}

(ARENDT, 2006), pois é através deles que o homem presume a sua verdade. Segundo essa autora, o discurso se institui no âmbito da ação coletiva; sem esta ação o discurso vira pura conversa que manipula, mas não comunica; sem a comunicação pelo discurso não há transitividade. A violência aniquila a "palavra e o discurso", ela não permite o falar, o ouvir, pautando-se apenas no ato agressivo. Como movimento de mudança, a ação coletiva mediadora do diálogo destrava o homem ${ }^{15}$, rompe as amarras e possibilita a liberdade do pensamento, o desenvolvimento das subjetividades e a mediação da pluralidade humana, em seu duplo aspecto de igualdade e diferença. Para Arendt (2010, p. 20):

Se não fossem iguais, os homens seriam incapazes de compreender-se entre si, ou de fazer planos para o futuro e prever as necessidades das gerações vindouras. Se não fossem diferentes, os homens não precisariam do discurso ou ação para se fazer compreender.

O discurso e a ação coletiva estão imbricados e são manifestações singulares da vida humana, e fazem do homem um ser político e constitutivo de um mundo comum ${ }^{16}$ e sem violência. Em diálogo com alguns conceitos de Hannah Arendt, Michel Foucault e Giorgio Agamben, consideramos que o poder é um elemento fundamental na vida do indivíduo e possui relação de aproximação e distanciamento com a violência, ou seja, ele está presente na prática do ato violento como mobilizador da potência e da força, e pode se fazer ausente quando associado à prática política, tendo em vista que a violência institui-se

\footnotetext{
${ }^{15}$ No centro do pensamento de Hannah Arendt sobre a condição humana está, de fato, a ação. Contudo, a condição humana do sujeito da ação enseja-lhe outras atividades que, embora pelo ângulo de análise da autora possam ser consideradas passivas, devem ser incluídas no âmbito da vida activa, porque atuam de modo a por no mundo constrangimentos e limites que balizam a ação. Arendt decide centrar seus esforços teóricos ao entendimento da vita activa, da esfera da ação humana, que ela denomina mesmo de condição humana.

${ }_{16}$ Para Dantas Neto (1999), a reflexão arendtiana sobre a ação não se deve deter ao sujeito, mas na espontaneidade do impulso que a faz emergir, junto com o discurso - e sobre os processos limitadores dos efeitos da ação no mundo.
} 
através de vidas apolíticas. Na concepção de Agamben (2002), o indivíduo que tem negada a sua existência política encontra-se encerrado na existência biológica, diferenciado, excluído e violentando pelo não acesso a uma vida digna ${ }^{17}$. Neste contexto de ausência da política, o autor incorpora, na discussão da violência, compreensões sobre o Estado, o poder soberano, este e sua força deliberativa no desenho dos limites da inclusão e da exclusão do indivíduo na vida política. Agamben (2004), ao analisar a estrutura da soberania no mundo atual e sua correlação com a condição violenta do Estado, resgatou a noção de Estado de exceção, ${ }^{18}$ que se define

como um regime da lei no qual a norma vale, mas não se aplica (porque não tem força), e atos que não possuem o valor de lei adquirem sua força. A força de lei flutua como um elemento indeterminado que pode ser reivindicado ora pela autoridade do Estado, ora pela autoridade de uma organização revolucionária. (AGAMBEN, 2002, p. 29).

Nos nexos estabelecidos entre Estado, violência e organizações revolucionárias, há espaços para se refletir sobre as instituições formativas que necessitam assumir responsabilidades pelo mundo, na perspectiva de Arendt (1994), reafirmando sua vinculação social transformadora através de práticas que estimulem a liberdade do pensamento e inibam ações desumanizadoras, assegurando a circulação da palavra e sua autoridade enquanto organização revolucionária que deve promover a inclusão da vida na política.

Ao refletir sobre o "Estado de exceção" e o poder soberano, Agamben (2004) apresenta considerações relevantes na discussão sobre

${ }^{17} \mathrm{O}$ sentido de vida aqui tratado articula-se em dois momentos: vida biológica, caracterizado pelo corpo e suas funções vitais; e vida política, o espaço da vida em comunidade.

${ }^{18}$ A noção de "Estado de exceção" foi elaborada inicialmente por Walter Benjamin. Não é nosso objetivo aprofundar as problematizações sobre o Estado de exceção, contudo, segundo Agamben (2004, p. 19), “A exceção é uma espécie de exclusão [...]. o que caracteriza propriamente a exceção é que aquilo que é excluído não está, por causa disto, absolutamente fora da relação com a norma; ao contrário, esta se mantém em relação com aquela, na forma de suspensão".

Latitude, Vol. 8, nº 1, pp. 33-62, 2014. 
violência, tendo em vista que o "Estado de exceção" é desenhado como uma relação presente na origem da política; tal relação trata da delimitação entre o que está incluso e excluso da política, do direito e da normalidade. Assim, a exclusão da vida na política corresponde à inclusão da vida incivilizada e violenta. $\mathrm{O}$ "Estado de exceção" mobiliza o poder de dar e retirar a condição de ser político, não se configurando em um ambiente ditatorial, mas em um espaço vazio de direitos.

O poder soberano, no contexto de um "Estado de exceção", tem o arbítrio de conduzir sobre a vida e a morte, produz zonas de indiferença, confundindo violência e direito, cria espaços de indistinção dentro do próprio Estado. Esses espaços, segundo Agamben (2002, p. 72),

[...] dissolvem as determinações do direito, que passam a ser suspensas, e nas lacunas deixadas pela ausência da lei e da regra, se produz a vida nua, compreendida como a vida restrita à sua dimensão biológica, marcada como condição apolítica e destituída de quaisquer direitos.

Na constatação de Agamben (2002, p. 19), a "vida nua" insurge em espaços de exceção, onde existe a plena ausência de ação política. A "vida nua" se constitui como uma categoria criada para o livre exercício do poder soberano sobre aqueles que subsistem em um mundo onde o direito não se efetiva. Podemos nos referir aos milhares de seres viventes, num estágio de "vida nua" que habitam os cortiços, albergues, Febens, "carandirus", favelas, conjuntos habitacionais populares etc. Lugares onde a exceção, além de regra, é paradoxalmente a única forma de inclusão. Os espaços sociais em que vidas são desqualificadas, em que os corpos são violados e as pessoas são convertidas em corpos "matáveis", teriam o "Estado de exceção" como referência e paradigma.

O "Estado de exceção" não é, portanto, o caos que precede a ordem, mas a situação que resulta da sua suspensão. Ele se faz presente em diversos espaços institucionais da sociedade contemporânea. Nesse sentido, a exceção é, verdadeiramente, segundo o étimo, capturada fora (excapere) e não simplesmente excluída. Para Agamben (2004) a exceção se encontra em uma extrema relação com algo que é incluído através de sua exclusão, condição que se reproduz nas compreensões da violência e da 
política, que são colocadas em contextos ambíguos de negação e limite, onde a condição de existir é a ausência do outro. Entretanto, no jogo de inclusão e exclusão da violência ou da política, há situações em que o poder soberano precisa exercer a violência para combater a violência e instituir a vida política.

Segundo Agamben (2002), a violência não pode ser totalmente incluída ou excluída do poder soberano. O Estado não pode abrir mão do uso da violência como instrumento de pacificação, tendo em vista a sua condição de instituidor da civilidade, mediante a necessidade de destituir a descivilidade como forma de manter o controle social. Desse modo, o poder soberano manifesta a necessidade de definir vidas politicamente desqualificadas, "vida nua" (despolitizada), em que a violência precisa ser exercida para reforçar o domínio, o poder e a força do Estado.

A violência cometida pelo Estado integra o processo civilizatório de manter o controle social e promover a justiça e o bem-estar coletivo através de regulamentações que devem ser obedecidas mesmo a contragosto de alguns. Toda a responsabilidade alocada no Estado, no que se refere à promoção da coesão social, faz de sua violência uma ação legítima ${ }^{19}$, e é funcionalmente diferenciada da violência cometida por outras instituições e pelos indivíduos. Mesmo com função social clara e institucionalizada, a violência promovida pelo Estado não perde a conotação de expressão de força que agride a condição humana e desqualifica a política.

\section{Classificar e distinguir - violências e crimes}

Como categorias complexas que indicam fenômenos manifestos na sociedade, a "violência" e o "crime" não podem ser assimilados em uma mesma matriz conceitual, nem compreendidos em definições estanques. Como explicita Maria Stela Grossi Porto (2000), com as constantes definições e redefinições do espaço sociocultural, a própria nomenclatura da violência e do crime segue os contornos de uma sociedade flexível e mutante. Para ser compreendida é necessário a percebermos como uma

${ }^{19} \mathrm{O}$ Estado é a única instituição que pode fazer o uso legítimo da violência. A expressão "monopólio da violência legítima" é de Max Weber (1970, p. 120) no livro A política como vocação. O monopólio da violência legítima significa que o emprego da coerção é função de exclusiva competência do Estado.

Latitude, Vol. 8, nº 1, pp. 33-62, 2014. 
ação difusa, como sugere José Vicente Tavares dos Santos (2009), que propõem o esboço do que ele chama de "sociologia da conflitualidade", um paradigma explicativo que busca compreender as práticas sociais consideradas violentas próprias da sociedade contemporânea - violência política, violência costumeira, violência de gênero, e um conjunto de outras violências que para este autor, revelam dilemas da sedimentação de um controle social, informal e formal que tem como fator desencadeante a violência difusa na sociedade contemporânea.

O debate sobre a violência e a criminalidade mobilizou nos últimos anos uma série de estudos e pesquisas nacionais e internacionais que visam buscar o entendimento deste fenômeno social, que instaura um campo de análise problemático e conflitivo, envolvendo diferentes categorias sociológicas, atores sociais e responsabilidades públicas. Condição que coloca o tema da violência como um problema da ordem pública, no caso particular do Brasil, a violência encontra-se situada na história particular da formação política do País (MISSE, 2006; ADORNO; PERALVA, 2005; ZALUAR; LEAL, 2001). Sérgio Adorno (2002) defende que a violência no Brasil constituiu-se como um fenômeno determinado sócio-historicamente e está associado à crise do sistema de segurança pública, ao crescimento das injustiças sociais e ao esvaziamento dos direitos. Em uma perspectiva similar à de Arendt, os trabalhos de autores brasileiros como Alba Zaluar $(1999,2002)$ e Vera Telles (1996) apontam que a violência danifica o projeto humano, pois nega o uso da argumentação como possibilidade de entendimento e de exercício político de sociabilidade.

Segundo Misse (2006), a temática da "violência" e as referências ao "mundo do crime" emergiram, portanto, numa série de estudos dos últimos anos, como questões vinculadas estreitamente aos deslocamentos recentes operados nas esferas estruturantes da vida popular que, antes de mais nada, colocavam em questão a promessa de contrapartida social do assalariamento industrial, "potencializados pela globalização" (TAVARES DOS SANTOS, 1999). A violência e o crime como fenômenos sociais instituem uma "sociabilidade violenta" 20 na forma como formulada por

20 A noção de sociabilidade violenta, originalmente desenvolvida por Luiz Antonio Machado da Silva (2004) e Michel Misse (2006), expressa como as práticas violentas e criminosas alteram as relações sociais de convívio, instituindo novas formas de convivência resultantes da insegurança e do medo, como sensações presentes no cotidiano. 
Machado da Silva (2004) e Misse (2006), que destacam que ela se manifesta na sociedade brasileira e se insere nos diversos espaços da vida cotidiana como práticas agressivas e hostis que anunciam novas formas de sociabilidades, marcadas pela insegurança e pelo medo ${ }^{21}$. Para Ruth Vasconcelos e Elaine Pimentel (2009), a compreensão da violência se articula também com dimensões sócio históricas, nos Estados do nordeste brasileiro, por exemplo, não podendo ser descartado do estudo da violência, os ranços ainda existentes do autoritarismo e do coronelismo, condições que põem a violência e a criminalidade como fenômeno social e cultural, que tem expressão difusa e fragmentada como um mosaico.

O fato é que violência e crime não são sinônimos, uma vez que os atos violentos e criminais podem estar contidos na mesma ação ou não. Há atos de violência que não se configuram em crimes, mas todos os crimes se configuram em violência, tendo em vista que o crime em si é uma violência enquadrada e reprimida pela lei. Enquanto a violência se refere ao constrangimento físico ou moral, a criminalidade é a expressão dada ao conjunto de infrações que são produzidas em um tempo e lugar determinado, constituindo-se em uma transgressão da lei e da norma, uma desobediência à imposição da regra jurídica. O crime é o resultado da violência, e esta é um fenômeno histórico-social, podendo estar presente em todas as práticas sociais, enquanto o crime é um fenômeno jurídico. Conforme Feltran (2008), a noção de criminalidade violenta indica o conjunto de atos ilegais e ilícitos nos quais se utiliza da força de coerção (violenta) ou da ameaça de sua utilização.

A representação da violência e do crime em uma sociedade não se situa apenas no âmbito jurídico-legal, mas é também social e se associa diretamente às formas de controle exercidas pelo Estado em relação ao ato e o que ele representa para a sociedade. Cada sociedade define nas convenções legais de seu país o que é considerado crime. Para Émile Durkheim $(2005,2006)$, a existência do crime é um fato social normal, embora sempre abominável, e logo punível à incidência do ato criminal.

${ }^{21}$ Essa sensação se associa à ideia de um mal que pode surgir em qualquer lugar e a qualquer momento, exacerbando-se pela crise de confiança e pela fragilização dos vínculos sociais que se encontram cada vez mais ameaçados (BAUMAN, 2008). 
O crime não se produz só na maior parte das sociedades desta ou daquela espécie, mas em todas as sociedades, qualquer que seja o tipo destas. Não há nenhuma em que não haja criminalidade. Muda de forma, os atos assim classificados não são os mesmos em todo o lado; mas em todo o lado e em todos os tempos existiram homens que se conduziram de tal modo que a repressão penal se abateu sobre eles. (DURKHEIM, 2006, p. 86).

Os atos criminosos e violentos estão presentes nas relações humanas nos mais remotos e diferenciados momentos históricos. Entretanto, os sentidos desses atos se encontram presentes nas interpretações dos efeitos que eles causam no indivíduo e na sociedade, já que os atos estão subordinados às convenções culturais, sociais e jurídicas que regem o contexto espacial, temporal e relacional em que eles se processaram (NORONHA, 2000). Salientando que o ato criminoso se pauta pela regulamentação, e não há crime sem lei que antes o defina, o ato violento se pauta na sua intensidade agressiva, explicitando-se através de diversas linguagens e representações, que transgridem o convencionado como certo, legal e ético, e estabelece, com o uso da força, deliberações que instauram novas formas de controle à ordem social.

O crime, como categoria sociológica é menos complexo do que a violência, considerando que o crime é objeto de regulamentação jurídica, seu entendimento é objetivado pela circunscrição penal, e a violência é um fenômeno difuso em que suas representações sociais dependem dos "valores e das crenças que estruturam e presidem a vida social" (PORTO, 2006, p. 5).

A difusão da violência na sociedade contemporânea é de difícil classificação, tendo em vista que a intensidade da ação agressiva se altera de acordo aos contornos subjetivos instituídos à representação dada pelo sujeito a determinadas ações que podem ser consideradas e enquadradas como violência para determinado sujeito e para outro não.

Na sociedade contemporânea, em que a violência se dissemina de forma banalizada, a classificação das formas de violência varia de acordo com os sentidos que os indivíduos atribuem a essa, podendo ser categorizada em macro e microviolências (CHARLOT, 2002; 
DEBARBIEUX, 2001; ZALUAR; LEAL, 2001; MISSE, 2006). A macroviolência se relaciona às lógicas do capitalismo que, obediente aos determinantes internacionais do mercado financeiro global, produz desigualdades sociais e econômicas entre os continentes e os países, aumentando a pobreza e diluindo os direitos humanos. A macroviolência é diluída e invisibilizada nas condições de vidas, possuindo efeitos nefastos na vida das pessoas, entretanto não conseguimos percebê-la de forma materializada em nosso cotidiano, pois ela se revela através de microviolências presentes nos conflitos e tensões recorrentes em nosso cotidiano, manifestando-se através de conflitos intersubjetivos, prática de atos incivilizados que muitas vezes se banalizam, até assaltos e agressões graves.

Conforme autores como Alba Zaluar $(1985,1994,1999)$ e Michel Misse (2006), os fatores que operam o crescimento das macro e microviolências são diversos e interconectados, podendo agir de forma direta ou indireta na mobilização do ato violento. Esses fatores podem ser organizados em dois eixos, que mobilizam os principais elementos geradores do crescimento da violência na contemporaneidade - o fator econômico-social e o fator cultural-ético-político. O fator econômico-social se refere ao modo de produção e às lógicas associadas à sua materialidade econômica, formas de acumulação e estruturação de classe, relação com o Estado e seus efeitos no gerenciamento das desigualdades sociais, na política de distribuição de renda e acesso aos direitos civis, elevação de qualidade de vida, e seus desdobramentos nas dimensões do emprego, salário, moradia, transporte, segurança, estudo, saúde; tudo que diz respeito à vida do indivíduo relacionada a esses aspectos. $\mathrm{O}$ fator culturalético-político se refere a um conjunto de ideologias, vícios e comportamentos reproduzidos socialmente e internalizados nas práticas sociais, a exemplo da impunidade e descrença com a Justiça; corrupção e crise das instituições formais de poder do Estado; desvalorização e descrença com a educação; crise da autoridade familiar; sensação de desprezo em relação aos direitos e os deveres; e sentimento de "desvinculação social". 


\section{Considerações Finais}

No delineamento da problematização do conceito sociológico da violência, o artigo explicitou as complexidades e contradições que se instituem em torno de sua polissemia, afirmou a violência como um fenômeno social dinâmico, que emerge das relações entre os homens e que contraditoriamente atinge o próprio homem. Ao tentar demonstrar a origem do conceito da violência referenciou o processo de transição do estado de natureza (selvageria) para o Estado civil (contrato, normas e regras) e todos os seus desdobramentos na postulação de códigos de civilidade. No processo de transição apresentado foram sinalizados os parâmetros de condutas sociais, que negavam as ações antissociais e incivilizadas. Definindo que os primeiros marcos para a compreensão da violência, fogem da banalização do mundo selvagem, podendo circunscrever a violência e o crime como violação de contratos instituídos, passiveis de punição e controle social.

$\mathrm{O}$ artigo expressou que após um longo período de intensa selvageria, vivenciamos na contemporaneidade um mundo de complexas leis, regras e normas, a evolução e o aperfeiçoamento dos códigos de controle foram constantes, mas a violência e o crime continuam a existir de formas diferenciadas e incidentes. Confirmando que a incivilidade como forma de negação da civilidade se mostrou não só presente, em períodos remotos de nossa sociedade, expresso em atos de violência e criminalidade, como aparecem atualmente como fenômeno crescente e muitas vezes naturalizados.

Ficou evidente no trabalho apresentado que a violência não é um fenomêno social recente, mas no transcurso dos períodos históricos, ela teve seus sentidos transformados e adequados aos novos códigos sociais, daí a ratificação da violência como uma construção social. Como uma ação que se institui no âmbito das relações entre os homens, ela se manifesta como um expressão social que envolve diversas variáveis e situações sociais aguçadas pela sociedade capitalista. Ela se encontra disseminada, e muitas vezes banalizada na sociedade contemporânea. Suas formas de manifestação acompanham as mudanças da ordem social, econômica e política, e nas instituições reguladoras, que impõem também novas configurações, instituições e modos de articulação que acabam retornando aos sujeitos nela implicados. 
Na complexidade analítica apresentada pela violência, enquanto fenomeno social, associamos a sua compreensão com a afirmação ou negação de outras categorias como poder, força e política. Conduzida e imposta pelo uso da força, a violência não é só a força física, mas também a simbólica, se revela como uma ação destrutiva que ameaça a autoridade e o poder e a diluição do diálogo como linguagem necessária no âmbito da política. Como uma ação antipolítica, a violência manifesta entre os homens aniquila o sentido e a força da palavra, brutaliza as relações sociais e condena o homem contemporâneo a conviver com a insegurança e o medo. Ao subjulgar o discurso e a ação coletiva, ao uso da força desmedida, o homem destitui o mundo comum, como um lugar de entendimento e sociabilidade.

A dialética que se constitui em torno do conceito da violência, dentro das intercalações dos elementos que marcam a civilidade e a incivilidade, disseminam-se no espaço social e faz insurgir comportamentos contraditórios associados às novas sociabilidades entre os homens, que alteram linguagens, significados e representações, a exemplo da ordem e do conflito, da defesa e do ataque, do formal e do informal, do legal e do ilegal, contradições que complexibilizam ainda mais o entendimento deste fenômeno, que cada vez mais se banaliza e se instala na relação entre os homens.

Nas problematizações esboçadas neste artigo, percebemos que o crime, como categoria sociológica, é menos complexo do que a violência, tendo em vista que ele é regulado por leis e códigos instituídos pela sociedade civil, diferente da violência que esta associada a um complexo de interpretações que se alteram a depender do tipo de intensidade e entendimento da forma de agressão. A evolução dos códigos sociais, através das leis modernas e a afirmação dos direitos humanos negam a violência ao mesmo tempo em que a reconhecem como um problema crescente na sociedade contemporânea. A violência como um mal que atinge a vida social deve ser combatido, pois ela agride a condição humana e os direitos civis e sociais, dequalificando as formas de sociabilidade e solidariedade entre os homens. 
Construção social da violência e a negação da civilidade

\section{Referências}

ABRIC, Jean-Claude. A abordagem estrutural das representações sociais. In: PAREDES MOREIRA, Antonia Silva; OLIVEIRA, Denize Cristina de (Org.). Estudos interdisciplinares de representação social. Goiânia: AB, 1998.

ADORNO, Sérgio.. Exclusão socioeconômica e violência urbana. Revista Sociologias, Porto Alegre, ano 4, n. 8, p. 84-135, jul./dez. 2002.

ADORNO, Sérgio; PERALVA, A. Dialogues sur la violence en France et au Brésil. Cultures et Conflits, v. 59, p. 5-9, 2005.

AGAMBEN, Giorgio. Homo Sacer: o poder soberano e vida nua. Tradução de Henrique Burigo. Belo Horizonte: Ed. UFMG, 2002.

. Estado de Exceção. São Paulo: Boitempo, 2004.

- O que resta de Auschwitz. O arquivo e a testemunha. Tradução de Selvino Assmann. São Paulo: Boitempo, 2008.

ARENDT, Hannah. A condição humana. 11. ed. Tradução de Roberto Raposo. Rio de Janeiro: Forense Universitária, 2010.

. O que é Política? Tradução Reinaldo Guarany. 6. ed. Rio de Janeiro: Bertrand Brasil, 2006.

- Sobre a violência. Tradução de André Duarte. Rio de Janeiro: Relume-Dumará, 1994.

BAUMAN, Zygmunt. Medo líquido. Rio de Janeiro: Zahar, 2008.

BOBBIO, Norberto. Estado, governo, sociedade: por uma teoria geral da politica. Tradução Marco Aurelio Nogueira. Rio de Janeiro: Paz e Terra, 1987.

. A era dos direitos. 11. ed. Rio de Janeiro: Campus, 1992. 
CLASTRES, P. Recherches d'anthropologie politique.Paris,Seul,1980

CHARLOT, Bernard. A violência na escola: como os sociólogos franceses abordam essa questão. Sociologias, Porto Alegre, ano 4, n. 8, p. 432-443, 2002.

DANTAS NETO. Paulo Fábio. Realismos surpreedentes: o lugar da ação no pensamento de Antonio Gramsci e Hannah Arendt. In: Caderno CRH, Salvador, n. 31, p. 41-84, 1999.

DEBARBIEUX, Éric. A violência na escola francesa: 30 anos de construção social do objeto (1967-1997). Educação e Pesquisa, São Paulo, v. 27, n. 1, p. 163-193, 2001.

DURKHEIM, Émile. Da divisão do trabalho social. São Paulo: Martins, 2006.

DURKHEIM, Émile. As regras do método sociológico. São Paulo: Martin Claret, 2005.

ELIAS, Norbert. O processo civilizador: formação do Estado e civilização. Tradução de Ruy Jungmann. Rio de Janeiro: Jorge Zahar, 1994. vol. 2.

Os alemães - a luta pelo poder e a evolução do habitus nos séculos XIX e XX. Tradução Álvaro Cabral. Rio de Janeiro: Jorge Zahar, 1997.

ENGELS, F. A origem da família, da propriedade e do Estado. 9. ed. Rio de Janeiro: Civilização Brasileira, 1984.

FELTRAN, Gabriel de Santis. Fronteiras de tensão: um estudo sobre política e violência nas periferias de São Paulo. Tese (Doutorado em Ciências Sociais) - Universidade Estadual de Campinas, Campinas, 2008.

FOUCAULT, Michael. Microfísica do poder. 13. ed. Rio de Janeiro: Graal, 1998. 
Construção social da violência e a negação da civilidade

2001.

. Vigiar e punir. História da violência nas prisões. São Paulo: Vozes,

. A ordem do discurso. 12. ed. São Paulo: Loyola, 2005.

. Em defesa da sociedade. São Paulo: Martins Fontes, 1999.

GRAMSCI, A. Cadernos do cárcere: introdução ao estudo da filosofia e a filosofia de Benedetto Croce. 2. ed. Rio de Janeiro: Civilização Brasileira, 2001. vol. 1.

HOBBES, T. Os elementos da lei natural e política. Trad. Fernando D. Andrade. São Paulo: Ícone, 2002.

JODELET, Denise. As representações sociais. Tradução Lilian Ulup. Rio de Janeiro: EDUERJ, 2001.

KALDOR, M. Global civil society: an answer to war. Cambridge: Polity, 2003.

KRAMER, H. L. Die Gewaltproblematik im franzosischen und deutschen Schulsystem. Opladen: LAMNEK S. (Ed.) Jugend und Gewalt, 1994.

LOCKE, John. Segundo tratado sobre o governo civil. São Paulo: Martin Claret, 2005.

MACHADO DA SILVA, Luiz Antonio. Sociabilidade violenta: por uma interpretação da criminalidade contemporânea no Brasil urbano. Revista Sociedade e Estado, Brasília, v. 19, n. 1, p. 53-84, jan./jun. 2004.

MARX, Karl ; ENGELS, F . Manifesto do Partido Comunista. Lisboa: Avante, 1999.

MICHAUD, Y. A violência. Tradução L. Garcia. São Paulo: Ática, 1989.

MISSE, Michel. Crime e violência no Brasil contemporâneo. Rio de Janeiro: Lúmem Júris, 2006. 
Malandros, marginais e vagabundos e acumulação social da violência no Rio de Janeiro. 1999. 413 f. Tese (Doutorado em Sociologia) - Instituto Universitário de Pesquisa do Rio de Janeiro (IUPERJ), Rio de Janeiro,1999.

MOSCOVICI, S. A representação social da psicanálise. Rio de Janeiro: Zahar, 1961.

MUCHEMBLED, Robert. História da violência: do fim da Idade Média aos nossos dias. Rio de Janeiro: Forense Universitária, 2012.

NORONHA, Edgar Magalhães. Direito Penal. São Paulo: Saraiva, 2000.

PORTO, Maria Stela Grossi. A violência entre a inclusão e a exclusão social. Tempo Social, São Paulo, v. 12, n. 1, p. 187-200, maio 2000.

RIFIOTS, Theophilos. Nos campos da violência: diferença e positividade. Disponível em http://www.cfh.ufsc.br/ levis/downloads/artigos/NCVDP.pdf. Laboratório de Estudos da Violência - CFH/UFSC, Florianópolis, 2006. Acessado em 21 de junto de 2014.

ROUSSEAU, Jean-Jacques. Do contrato social. São Paulo: Abril Cultural, 1978.

TAVARES DOS SANTOS, José Vicente. Violência em Tempos de Globalização. São Paulo: Hucitec, 1999. . Violências e conflitualidades. Porto Alegre: Tomo Editorial, 2009

TELLES, V. S. A cidade nas fronteiras do legal e ilegal. Belo Horizonte: ARGVMENTVM, 2011.

Questão social: afinal do que se trata? Revista São Paulo em Perspectiva, São Paulo, v. 10, n. 4, p. 85-95, 1996. 
Construção social da violência e a negação da civilidade

VIGILANTE de colégio estadual é baleado por aluno de subúrbio de Salvador. A Tarde, p. 10, 18 out. 2013.

VASCONCELOS, Ruth e PIMENTEL, Elaine. Violência e criminalidade: em mosaico. Maceió: EDUFAL, 2009, pp. 81-116.

WACQUANT, Loic. As prisões da miséria. Rio de Janeiro: Zahar, 2001.

WEBER, Max. A política como vocação. São Paulo: Cultrix, 1970.

ZALUAR, Alba. A máquina e a revolta. São Paulo: Brasiliense, 1985.

. Condomínio do diabo. Rio de Janeiro: Editora da UFRJ/Revan, 1994.

ZALUAR, Alba. Um debate disperso: violência e crime no Brasil da redemocratização. São Paulo em Perspectiva, São Paulo, v. 13, n. 3, p. 3-17, 1999.

; LEAL, Cristina. Violência extra e intramuros. Revista Brasileira de Ciências Sociais, São Paulo, v.16, n. 45, p. 145-164, 2001.

Enviado:

05.06.2014

Aprovado:

04.09.2014 